\title{
2017 The American Association for Thoracic Surgery Presidential Address: Ancora imparo: Always learning
}

\author{
Thoralf M. Sundt, MD
}

\author{
From the Division of Cardiac Surgery, Massachusetts General Hospital; and Harvard Medical School, Boston, \\ Mass. \\ Read at the 97th Annual Meeting of The American Association for Thoracic Surgery, Boston, Massachusetts, \\ April 29-May 3, 2017. \\ Disclosures: Author has nothing to disclose with regard to commercial support. \\ Received for publication Dec 14, 2017; accepted for publication Dec 14, 2017. \\ Address for reprints: Thoralf M. Sundt, MD, Division of Cardiac Surgery, Massachusetts General Hospital, 55 \\ Fruit St, Boston, MA 02114 (E-mail: tsundt@mgh.harvard.edu). \\ J Thorac Cardiovasc Surg 2018; 155:837-46 \\ $0022-5223 / \$ 36.00$ \\ Copyright (C) 2017 by The American Association for Thoracic Surgery \\ https://doi.org/10.1016/j.jtcvs.2017.12.053
}

As you can see I have led a life of extraordinary privilege. None has been greater than the privilege to participate in this organization and to share this time with you today.

Ancora imparo is a phrase attributed to Michaelangelo that means always learning. I think it is a particularly appropriate topic here in Boston, surrounded as we are by so many institutions of higher learning.

It is customary to begin with an homage to one's mentors. The truth is that I love this part. I think most surgeons do, perhaps because the defining event of our specialty is so personal and so human. We seek heroes_at least I do_-and this is my opportunity to contribute to the oral history of our specialty and to familiarize the younger members of our specialty with some of my heroes. I have to say that this comes at significant risk because leaving out individuals who have been critical to my own success is inescapable; there have been so many. So I have tried to orient my comments here around lessons I have learned of particular value.

In medical school I witnessed the quiet power of a kind voice and a caring heart in commanding reverence and respect. Vincent Gott was not the stereotype I had expected of a cardiac surgeon.

At Massachusetts General Hospital (MGH), Bill Daggett showed me the value of a systematic, thoughtful approach to every step of every procedure, and generously shared that knowledge. Cary Akins, a fellow Minnesotan, showed me that an operation can be choreographed flawlessly from beginning to end. Cary took special interest in me as a resident and was welcoming to me on my return. Thank you Bill and Cary.

Certainly my most formative time as a cardiac surgeon was in St Louis. If you look closely at the faculty seated in the first row of this photograph (Figure 1) you will see 5 presidents of this organization and 2 presidents of the Society of Thoracic Surgeons. Tom Spray taught me the value of efficient decision making and decisive action in the operating room, Alec Patterson what it is to have a true mentor and friend, Joel Cooper the excitement of

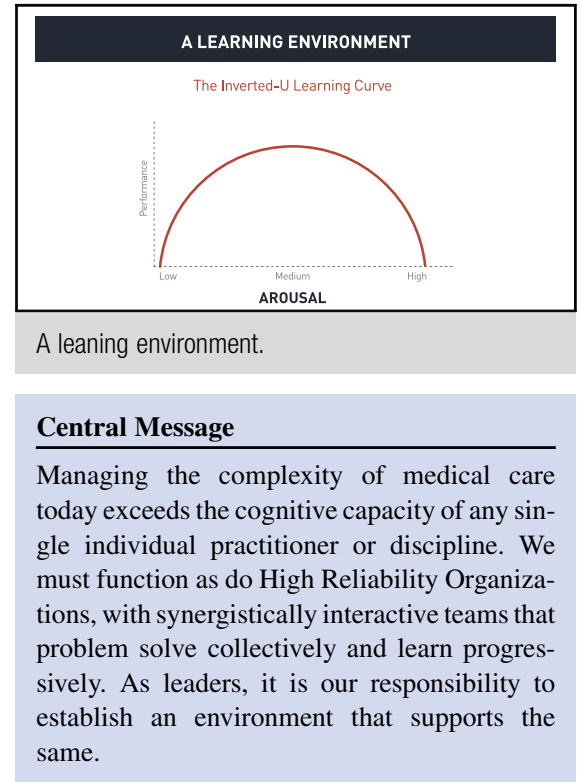

solving an unsolvable problem, and from Tom Ferguson I learned the importance of a generous spirit. He was one of the few to serve as president of both the Society of Thoracic Surgeons and the American Association for Thoracic Surgery. Nick Kouchoukos showed me a solid, safe, patient-centered approach in the operating room. I think I have patterned my own operative style more after him than anyone else. And from Jim Cox, the architect of this remarkable collection of talent, I learned the importance of building the team.

I was fortunate to work for, and then with, Magdi Yacoub, at Harefield. He is the archetype of the surgeon-scientist. $\mathrm{He}$ is a role model not only for his professional accomplishments but also the virtually universal high regard in which he is held by his trainees. From him I learned the value of simplicity, confidence, and creativity.

"Consider the needs of the patient first" is the North Star at Mayo Clinic. I learned that if you adhere to that simple

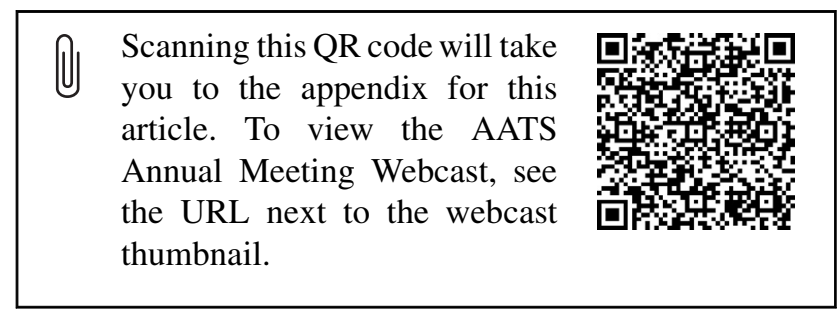




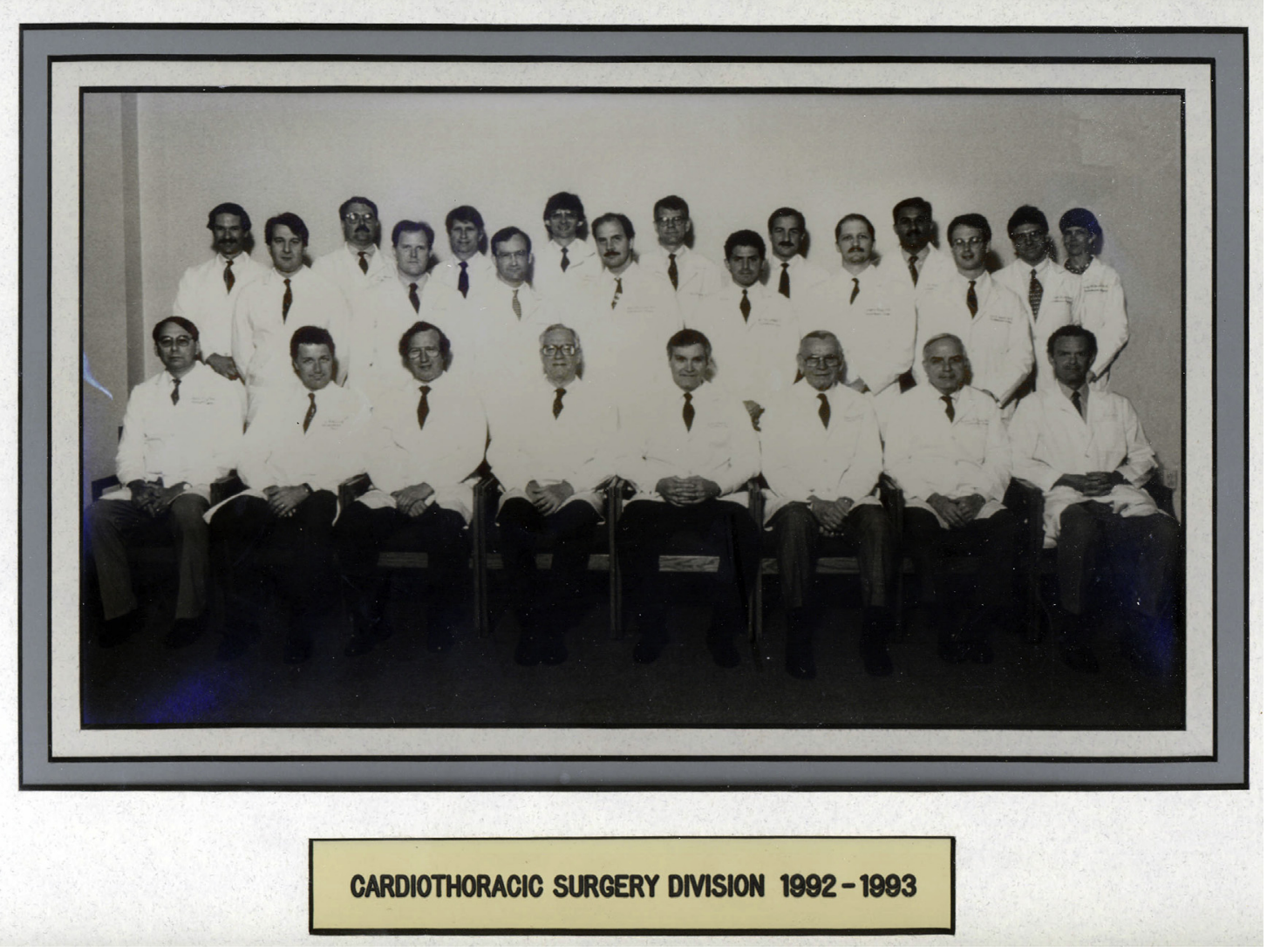

FIGURE 1. Division of Cardiothoracic Surgery at Washington University.

rule you cannot go far off course. Being accepted as a colleague by this group of individuals was as high a compliment as a clinical surgeon can receive. I am also most grateful for the opportunity for my son to grow up in that idyllic Midwestern town.

From David Torchiana, a most trusted advisor, I continue to learn the value of a deeply principled approach to leadership. Torch more than anyone gave me the opportunity to return to $\mathrm{MGH}$, a truly unique institution. Established as a hospital for the indigent more than 200 years ago, it maintains a commitment to care of the community. It is a privilege to work at MGH.

And of course I learn every day from the remarkable individuals that make up the MGH Division of Cardiac Surgery (Figure 2). Jim Cox, I never thought I would see a division to compare to the one you had assembled, but I was wrong. And here it is.

And of course I learn from all the other members of our cardiac surgery team-too many to count. Together we accomplish remarkable things. Thank you

But among all of these role models and mentors, by far the most important was my father (Figure 3). He was modest, committed, confident, and courageous. He taught me that it is a surgeon's responsibility always to exercise "brutal honesty and ruthless self-reflection." This is what the Accreditation Council for Graduate Medical Education (ACGME) calls practice-based learning. Given an admittedly somewhat melancholy personality at baseline, it is what my family calls hard to live with. Because our families pay a price, too, when bad things happen to patients if we are moody or self-absorbed.

But confronting failure is a critical step in learning from our experience. And that is what I want to share with you today-what I have learned about the value of teams and teamwork, and the role we play as leaders of those teams. My argument is based on what I have learned about complexity, cognition, and collective intelligence.

Learning is fundamental to us as humans. It is a basic need. For internally motivated people, Daniel Pink would argue that it is part of what drives us - the drive to master a subject. We have all seen it. Individuals will accept a job with you and stay with you despite offers for higher pay elsewhere if they are learning.

Our universities stand as monuments to learning and we are willing to go deeply into debt for an education-or for our children's education-thanks Mom! In fact this event, this meeting, this organization are all about learning. It is my bet that that is why you are sitting here now.

I had a transformational experience at this meeting in 1999. It was in New Orleans. I was sitting toward the 


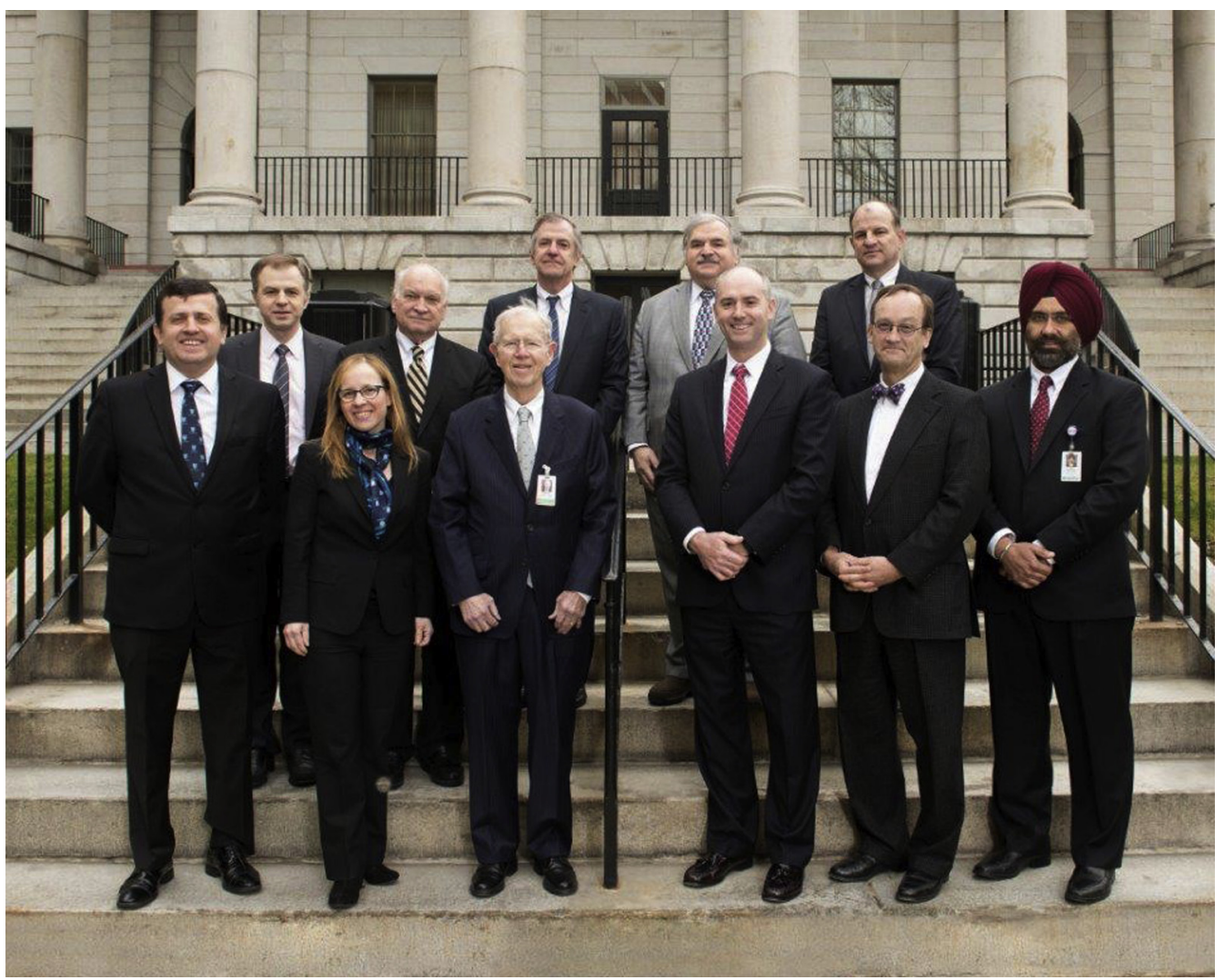

FIGURE 2. Massachusetts General Hospital Division of Cardiac Surgery. Front row (left to right): M. Villavicencio, N. Roy, W. Daggett, D. D’Alessandro, T. Sundt, and A. Jassar. Back row (left to right): S. Melnitchouk, D. Cameron, J. Madsen, G. Vlahakes, and G. Tolis.

back of the room when I heard a remarkable presentation by Marc de Leval. I knew as I listened that it was truly original, truly different. It was about factors impacting the outcomes of congenital heart procedures, not patient anatomy or comorbidity and not surgical technique, but other factors that impact individual and team performance: Human factors.

My cognitive IgM converted to IgG in 2002 when de Leval delivered the honored guest lecture titled "Beyond Flatland." He refers to a remarkable book written more than 100 years ago by an English schoolmaster describing an encounter between the 2-dimensional being named $\mathrm{A}$ Square, and a 3-dimensional being named A Sphere. The story dramatizes the impact of individual perspective on our interpretation of the world, and by implication how our mental framework impacts our perceptions of the problems we face and the solutions we see. It dramatizes the impact of adding another dimension to our understanding.

You see, when I was an intern, I thought as an intern. I felt responsible for everything all the time. There were no excuses. I felt a profound sense of personal accountability. Work hard and if bad things happened, work harder. I was a very good intern! And I learned to trust no one.
It was an era in which if you made a mistake you were likely to be asked, "Are you stupid or do you just not care?" Or in the operating room you might hear: "I just wish there were two of me and none of you," or: "If I were an octopus, I would not need any of you."

It was a simple, deterministic, Newtonian world of individual performance. Does it sound familiar to anyone else?

But as I have grown older I have discovered that it is not so simple. Bad things still happen, despite hard work and the best of intentions, and I still make mistakes. De Leval helped me understand why. He added a dimension to my understanding. You see, it turns out, life is complicated. In fact, it is complex.

And so began my own journey out of Flatland.

\section{COMPLEXITY}

For an annotated suggested reading list, please see Appendix 1.

De Leval introduced us to Ilya Prigogine and the concepts of complexity and chaos. The more I learn about them the more I see them all around me in my daily life, and the more I am struck by their appearance in fields of study as disparate as economics and military strategy. Prigogine describes stable and unstable equilibria (Figure 4). They 


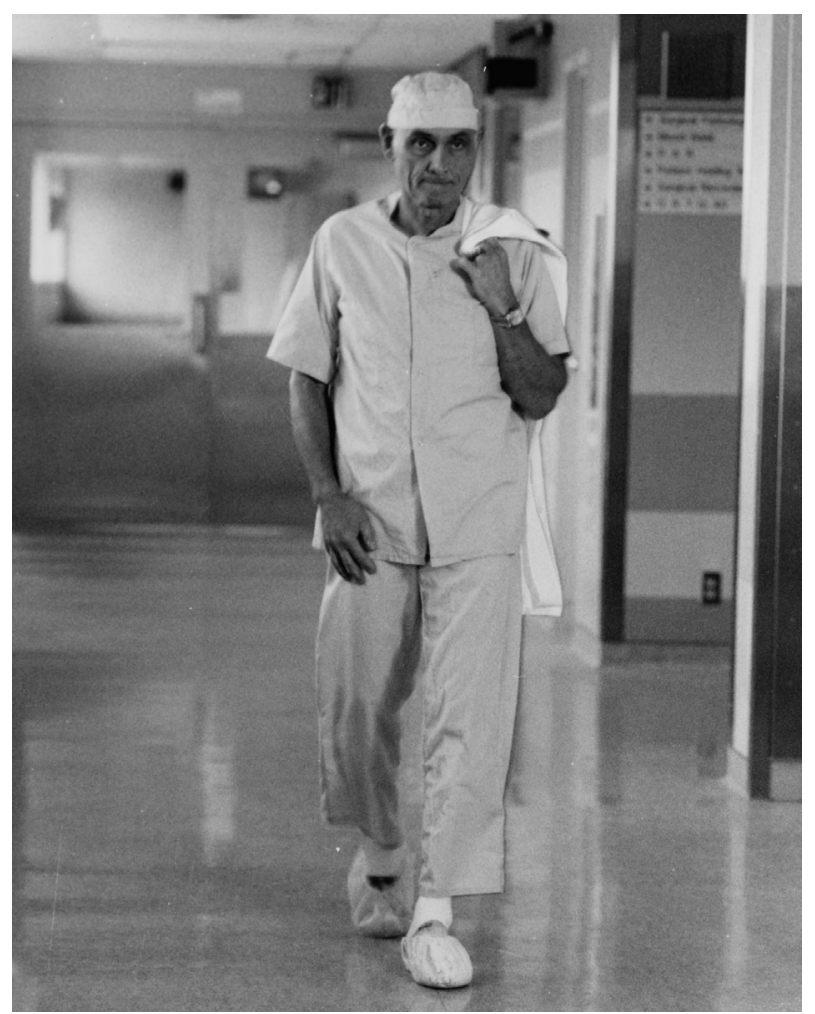

FIGURE 3. The author's father, Thoralf M. Sundt, Jr, MD.

appear similar in the moment of equilibrium, but small changes in stable systems produce only small effects and they return themselves to normal. Unstable dynamic systems are sensitive to initial conditions and small perturbations lead to dramatic nonlinear effects. And they do so in unpredictable ways. Will the ball fall to the right or to the left? They are much more common in the world around us. Living systems are unstable. They are what the new discipline of complexity science is all about: Away from reductionist approaches in favor of holistic perspectives.

\section{EQUILIBRIUM}

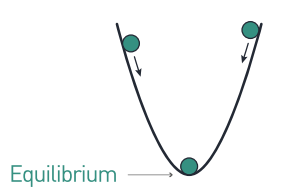

STABLE

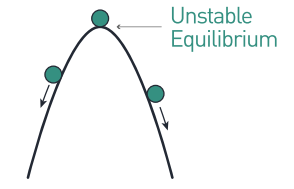

UNSTABLE
FIGURE 4. Stable and unstable equilibria look similar in the moment of equilibrium, but behave much differently in response to disruptions (after Prigogine I. The End of Certainty. 1997 New York: The Free Press; 1997:30).
The observation of nonlinearity is not new. It is what is behind the old proverb "for want of a nail the shoe was lost, for want of a shoe the horse was lost, for want of a horse the rider was lost, for want of a rider the battle was lost" and so on. It is how a single shot in Sarajevo can trigger a global conflict costing millions of lives, or a simple act of personal dignity can help to catalyze social change.

This is the world I recognize. Not one of Newtonian predictability but one of complexity and unpredictability. This world is dramatized in the movie The Curious Case of Benjamin Button (based on the short story by F. Scott Fitzgerald) of a man who grows younger rather than older. If you have not seen it, his love interest Daisy is hit by a cab ending her ballet career.

If only one thing had happened differently: If that shoelace hadn't broken; or that delivery truck had moved moments earlier; or that package had been wrapped and ready, because the girl hadn't broken up with her boyfriend; or that man had set his alarm and got up five minutes earlier; or that taxi driver hadn't stopped for a cup of coffee; or that woman had remembered her coat, and got into an earlier cab, Daisy and her friend would've crossed the street, and the taxi would've driven by. But life being what it is-a series of intersecting lives and incidents, out of anyone's control-that taxi did not go by, and that driver was momentarily distracted, and that taxi hit Daisy, and her leg was crushed.

So there you have it - a movie recommendation, too!

Small events can have big effects. The mathematics behind this was explored in the 1950s by Edward Lorenz at Massachusetts Institute of Technology as he modeled weather prediction using massive mainframe computers. He saw that tiny differences in input parameters resulted in wildly different outcomes. This is nonlinearity. It is the origin of the so-called butterfly effect: The notion that a tornado in Texas could be traced back the flapping of a butterfly's wings over Brazil.

It is a world in which equations as simple as force $=$ mass $\times$ acceleration have given way to statistical mechanics and probability distributions. I have to admit I lament this a bit. I enjoyed freshman physics but I dropped physical chemistry the first day when they showed us the Schrodinger equation!

Jeffrey Kluger provides what is for me a more accessible treatment of complexity, chaos, and most importantly complex adaptive systems. Being complex is not the same as being complicated. A watch is complicated, but it is entirely predictable. Complexity is different. It is "the region between order and disorder that gives you complexity" according to Nobel Laureate Murray Gell-Mann. It is the space in which interesting things happen (Figure 5). It is a world of random effects, and 


\section{COMPLEX, NOT JUST COMPLICATED}

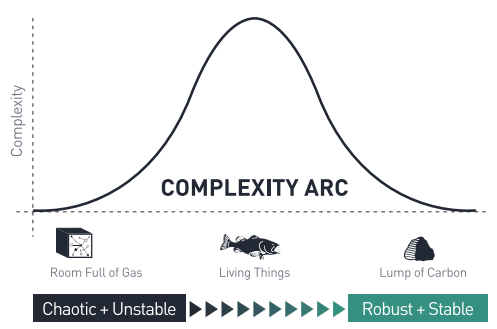

FIGURE 5. Living things, from individual organisms to populations, demonstrate complexity (after Kluger J. Simplexity. New York: Hyperon; 2008:28).

most intriguingly a world of self organization. This is what is so interesting about complex adaptive systems. They are complex-composed of many diverse autonomous parts, they are interdependent-linked as a system, and they adapt - they change in response to the environment and to each other. How they change depends critically on the nature of the interactions among those components.

Complex adaptive systems are different than the sum of their parts; in some cases they are more and in some cases less. Complex adaptive systems demonstrate emergent properties. They are unpredictable, too. This is what is exciting about team sports. Could anyone really predict a victory for the Patriots 25 points down in the third quarter of the Superbowl?

This unpredictability gives us more than entertainment, however; it poses problems. Charles Perrow coined the term "normal Accidents" to convey the inevitability of systems failures in truly complex endeavors from nuclear power to petrochemical plants. He also highlights the difficulty in diagnosing what went wrong when interactions are tightly coupled and complex in nature-evidence Three Mile Island.

The implication of this is that we must think beyond error prevention because we simply cannot prevent them all. This is why checklists alone will not solve our problems. Our focus needs to be on error management to include detection and recovery.

This is what High Reliability Organizations (HROs) are all about: Organizations and industries that consistently function with a lower-than-expected number of accidents given their complexity. This is particularly important in high consequence endeavors. HROs are structured with intention to deal with the unexpected.

What is the relevance of this to us as surgeons? I do not claim to understand chaos theory deeply — strange attractors and iterative maps-I have no doubt that there are many in this room who understand it far better than I. But I am intrigued by it and I am eager to learn. And I think that this is all relevant to us as because our world (our patients, the procedures we perform, and the institutions in which we perform them) are increasingly complex. Certainly the consequences of failure are severe. What this suggests to me is that no matter how much we care, and no matter how much we try, accidents, mistakes, and mishaps will occur. Individual effort is not enough.

\section{COGNITION}

Complexity is half of the problem: The other half is us. As it turns out, our brains have evolved to deal with complexity. Malcolm Gladwell wrote about it in Blink: The Power of Thinking Without Thinking. With a deluge of sensory input coming from all around us, we have evolved subtle ways to gather, prioritize, and analyze information rapidly against a background of experience nuanced by emotion. We make judgments constantly based on limited information and in ways that we ourselves do not understand. What is expertise? Intuition? Is the Getty Kouros genuine or is it a fake? Gladwell calls it thin slicing. What is the patient's diagnosis? Are they sick? Do they need to go back to the operating room?

My first exposure to these other modes of thinking was via neurobiologist Anthony Damasio. Based on studies of patients with brain injuries, he explored the influence of our limbic system - our emotional brains-on our decision making. How did you decide which seat to sit in today? How will you pick from the lunch menu we are all thinking about this time of day? We may not be as coldly rational as we would like to think. Where do those gut feelings come from? It turns out our amygdyla is actually activated in circumstances of uncertainty.

Gary Klein has studied what he calls naturalistic decision making. How do so-called experts think? And where does their creativity come from? Based on pattern recognition and mental simulation, experts make fast judgments in contrast to novices, who think slowly and algorithmically. We have all been amazed to see master clinicians make a complex diagnosis almost instantaneously. And yet even experts will sometimes make what we call rookie mistakes. The benefits to this kind of fast thinking are speed. The risk is that we may be wrong.

Daniel Kahneman and Amos Tverski focused on exactly these pitfalls in fast thinking in work that ultimately lead to a Nobel Prize and the establishment of the field of behavioral economics. Michael Lewis has written about this partnership. They identified systematic biases in our thinking that derive from our heuristics-our cognitive shortcuts-that we use every day to deal with the complexity around us. Our brains have evolved to play the odds and to seek out patterns. The result are some peculiarities. Some quirks.

Examples of biases are anchoring, which is the subtle impact a random number in the environment can have on 
our thinking. Representativeness, availability, framing, and halo effects all have an impact on our judgment and decision making when we are in fast-thinking mode.

But we have another mode of thinking as well termed slow thinking. Our slow-thinking brains are deliberative and logical. We use them for calculations. But they require concentration and energy, and most of us are lazy. We prefer to use our fast, intuitive brains.

You can feel it in action yourself. Quickly answer this question: 23 people are in a room. What is the likelihood that 2 will have the same birthday? Our fast brains tell us it is unlikely, but if you do the math it turns out the likelihood is $50 \%$.

Here is another: A baseball and a bat cost $\$ 1.10$. The bat costs $\$ 1$ more than the ball. Quickly: How much does the ball cost? Most will say it is obvious: 10 cents, but of course the ball costs 5 cents and the bat $\$ 1.05$.

Anchoring can be demonstrated by asking one group to quickly estimate the product of $8 \times 7 \times 6 \times 5 \times 4 \times 3$ $\times 2 \times 1$ and another group to quickly estimate the reverse: $1 \times 2 \times 3 \times 4 \times 5 \times 6 \times 7 \times 8$. The guesses will systematically be higher for the former than for the latter. Our slow brain tells us they are the same, but our fast brains are anchored to the first number in the sequence.

How is all of this fun and games relevant? We use our fast brains a lot. We use them every day as clinicians. Fast thinking is particularly important when decisions must be made quickly and on the basis of incomplete information. This sounds like old-fashioned clinical judgment to me-like the foot of the bed test, as it were.

And using our fast brains is where we feel comfortable as experts. This is where our emotional brains are happy. This is where we have the feeling of knowing. This is where we are in the psychological state of flow. This is where we feel certain of ourselves.

But that sense of certainty also puts us at risk. To consider the possibility that we are wrong requires that we shift back to our slow brains. It demands energy and concentration to hold in our minds simultaneously at least 2 contrasting possibilities. Our fast brains do not work that way. This is why time seems to slow down when we stop and question ourselves. Our language even reflects this truth.

How can we know when we are wrong? What does it feel like to be wrong? It feels the same as being right—right up until the moment that you discover the truth. Katherine Shultz has argued that there is no such thing as a feeling of being wrong-only a feeling of having been wrong. Her book Being Wrong needs to go on that list of books you are making. It is superb. Catch her TED talk, too.

Furthermore we are at risk of exercising confirmation bias. This may be underappreciated, but it is not a new concept. Francis Bacon described it in the New Organon:
"Once a human intellect has adopted an opinion... it draws everything else in to confirm and support it. Even if there are more and stronger instances against it...." As it turns out, there are data to show that experts in particular underestimate the degree of their own uncertainty. The recognition of the fallibility of experts-skepticism of received knowledge-is the very foundation of the enlightenment. In a crowd confirmation bias becomes group think and we end up with a disaster like the Bay of Pigs, or in our own field, what I think is a rush into an overly aggressive approach to bicuspid aortopathy.

Our remarkable resistance to recognizing that we can be so wrong and recognizing the role of random chance in our lives with the associated uncertainly and lack of control is what leads us to stubbornly believe that the stock market can be timed. This is what led to a global economic collapse from which we still have not recovered. We are fooled by randomness when we interpret the past, by what is called the primitive logic fallacy or affirming the consequent. This is the belief that it was all predictable if only we had connected the dots. But of course it was not! Complexity science tells us so. The problem is worse, writes Nicholas Taleb, when we try to predict the future; when we try to predict the occurrence of Black Swans.

The trouble is we don't know what we don't know. I will resist the urge to quote Donald Rumsfeld, and instead recall David Foster Wallace's commencement speech "This Is Water": ...2 young fish are swimming along when an older fish swims by. "Morning boys, how's the water?" The young fish look at each other and one asks, "What the hell is water?"

\section{COLLECTIVE INTELLIGENCE}

It should come as no surprise to you by now that I believe the solution to our conundrum is teams. I hope what I have shared with you up to has not been too much of a downer: Complexity and the challenges it presents-unpredictability, nonlinearity, and emergence as well as the power and pitfalls of human cognition in dealing with the complexity that surrounds us, biases, and being wrong.

But surgeons are optimists. We are problem solvers. I am convinced the solutions lie within the very complexity we just described. The most interesting aspect of complex adaptive systems is their property of self organization. This explains the paradox of the existence of organized life forms in a universe of increasing entropy. And complex adaptive systems are all around us. In fact we are in one right now in this room. Multiple agents, interacting with one another, being changed by those interactions and, I hope, learning.

The solution to the challenges of dealing with the complexity we face in medicine today is in high-functioning teams that are more than the sum of their parts. The antidote 


\section{PERSONALITY TYPES}

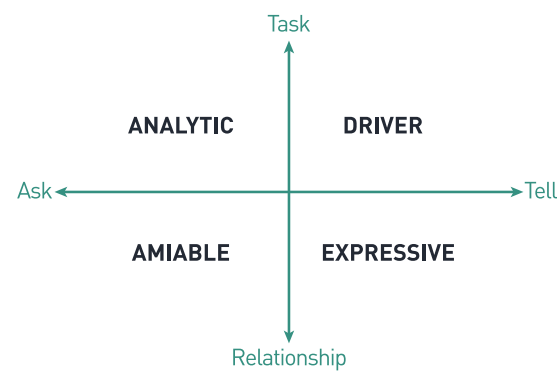

FIGURE 6. One of many matrices to describe personality orientations, this is simple and useful for understanding yourself and others.

to group-think is diversity of opinion. The defense against misperceptions is multiple perspectives.

There is genuine value in highly functional teams when addressing complex problems. And as leaders all of us in this room we can and do impact those teams. The keys to those teams are the agents-the members of the team - and the nature of the interactions; that is, how they adapt and change. How they learn.

What do we know actually know about teams? During my time at Mayo I was introduced to some business school principles. In particular I remember learning about personality types and the importance of including different types on the team (Figure 6). I am a task-oriented Driver and a total loss in the emotionally sensitive Amiable quadrant. Given a tough decision that requires either sacrificing a relationship to accomplish a task or sacrificing a task to preserve a relationship, I will prioritize the task. I am not proud of it, or ashamed of it. It is not inherently good or bad, right or wrong. It's just the way I'm built. And I have gotten things done-but I have paid a price for riding roughshod over people. I have also learned that by having relationship-oriented people on my team, I can hold that tendency more in check. Now, rather than it driving me crazy when the Amiables spend time chit-chatting at the

\section{VALUE OF TEAM DIVERSITY IN PROBLEM SOLVING}

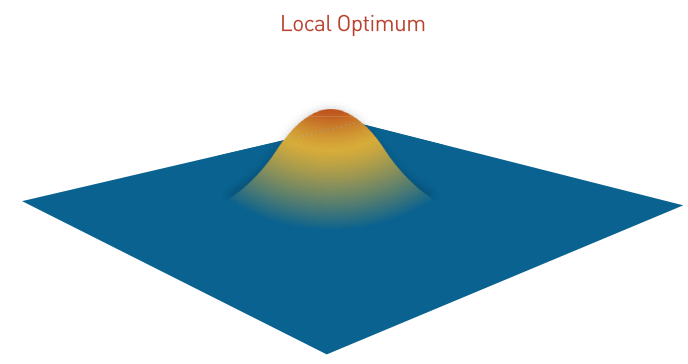

FIGURE 7. Faced with a complex problem, an individual will use their own set of cognitive tools to find a "best solution" or "local optimum." beginning of a meeting, I appreciate their diversity from me. And I don't have to talk!

As it turns out, clear arguments-in fact mathematical arguments - can be made for the value of diversity on the team as well. I will not digress into social or political issues here although I believe they are important and particularly timely. Instead I will focus on the science of cognitive diversity and note in passing that cognitive diversity tends to track with identity diversity.

The great mathematician and statistician Sir Francis Galton described the classic example of "the wisdom of the crowd." Attendees at a county fair were asked to guess the weight of a steer. They came within $1 \mathrm{lb}$. Remarkable! How can this be? It is random chance?

Scott Page is a professor of complex systems at the University of Michigan. I picked up a video lecture course of his on my own but was reintroduced to him by Rich Prager last year and was blown away by his mathematical arguments for the value of team diversity when facing complex problems. I cannot do full justice to his arguments, but will just tantalize you with two, one related to prediction and the other to problem solving.

Page shows mathematically that crowd error is always less than the average error of the individual in the crowd, not necessarily less than any particular individual, but more accurate than the average. But more importantly I think, he shows that the diversity of the predictions; that is to say, the difference between each individual's estimate and the average, is always less than that of the average individual. Those differences are based on different mental models and on different experiences resulting in differences in base rate bias, for example. The important result is that in the end, the accuracy of the crowd estimate depends as much in on the diversity of predictions as does on the accuracy of individual estimates. It is as important to have a diverse crowd as a smart one. At least for complex problems.

That is about prediction. What about problem solving? This is a little harder to convey, but I think this graphic helps (Figure 7). Switch to slow thinking and imagine that the universe of solutions to a particular complex problem can be represented as a landscape with the height of each peak representing the quality of the solution. Each individual working on solving the problem will use their own set of problem-solving tools to find their best solution, which is their "local optimum." This local optimum may or may not be the best option of all or the "global optimum."

A talented but homogeneous team with similar background and perspective using similar problem-solving tools will likely come up with similar solutions but a diverse team will come up with multiple different optima, one of which may truly be the global optimum (Figure 8). Diversity increases the chances of finding the best solution by chance. This is of course the most important lesson Galton's cousin 


\section{VALUE OF TEAM DIVERSITY IN PROBLEM SOLVING}

\section{Multiple Different Local Optima}

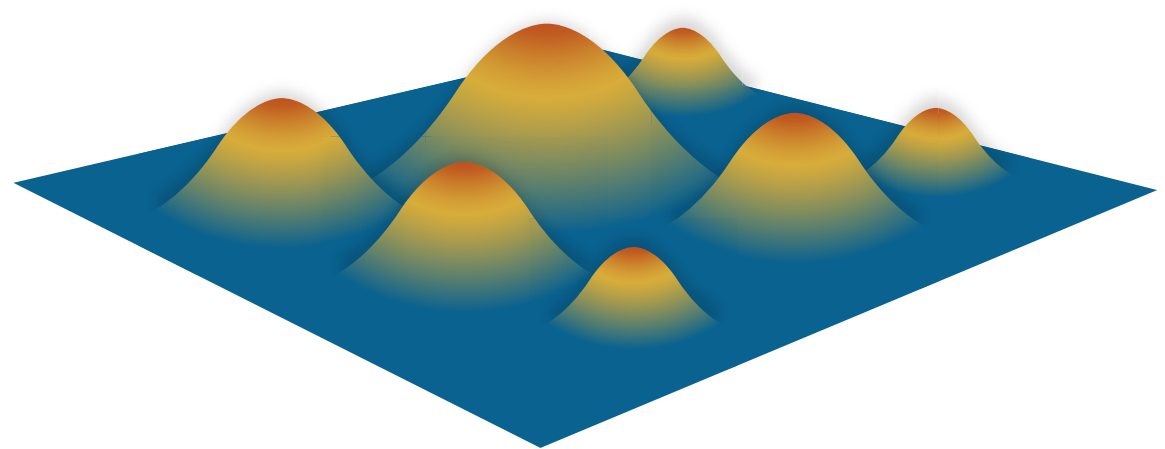

FIGURE 8. Multiple individuals working independently will identify their own local opitima, one of which might truly be the best possible solution—the "global optimum."

discovered on the voyage of the Beagle. Charles Darwin saw that natural selection exerts pressure, but it is diversity that generates the options.

Diversity is necessary, but is it sufficient? What is special about complex adaptive systems is the interaction piece, which is to say the ways they adapt. In biology this is the power of genetic recombination. In the more general case, if the problem solvers interact productively and use their tools in complementary fashion, they will help move one another off of their own individual local optima to find a global optimum that none alone would have discovered on their own (Figure 9). This is synergy. Synergy is the difference between another useless administrative meeting and an exciting, generative one during which everyone shares opinions, changes their views a bit, and collectively come up with an entirely original idea. It is also what improvisational comedy is about. It is the nature of the interaction is the key.

The difference between a diverse workgroup group of individuals and an effective team is synergy. Yes shared goals, compelling vision, and all that business-school speak is important, but there is more. Amy Edmonson argues that

\section{SYNERGY}

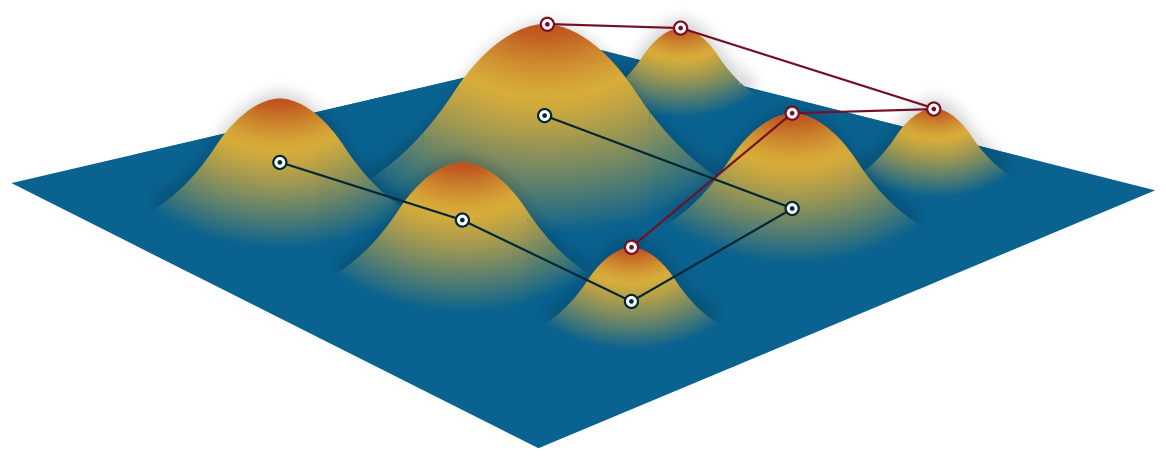

FIGURE 9. Synergistic interactions among team members leverages their diversity to identify the best possible solution to a complex problem. 


\section{SAFETY WITH ACCOUNTABILITY}

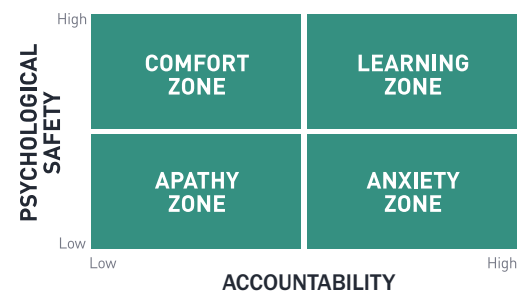

FIGURE 10. Safety and accountability are not incompatible (after Edmondson A. Teaming. San Francisco, CA: John Wiley and Sons; 2012:130).

the key to transforming a workgroup to a high-performing team is learning. She talks about teaming as a verb, not a noun. It is an active process that requires both cognitive and, unfortunately for us task-oriented personalities, affective skills. The aim is to create a "learning organization"; that is, a culture that encourages learning through open interactions in a psychologically safe space. Safe to share success and safe to share failure.

I am not going to claim failure is necessarily a good thing, but it is universal. Teddy Roosevelt talked about it at the Sorbonne: "The credit belongs to the man who is actually in the arena ... who errs... because there is no effort without error and shortcoming."

I also want to clearly state that a psychologically safe space does not imply one is free of accountability. Safety and accountability are not incompatible (Figure 10). Accountability in fact is essential to learning. But we need to overcome the shame: "Are you stupid or do you just not care?"

And a safe environment does not mean a casual environment, either. The aim is improving collective performance. Neurobiologists are clear: Optimal learning requires an appropriate amount of arousal (Figure 11). When I was an intern that meant fear. But too much fear quite literally shuts down learning. Our primitive brains

\section{A LEARNING ENVIRONMENT}

The Inverted-U Learning Curve

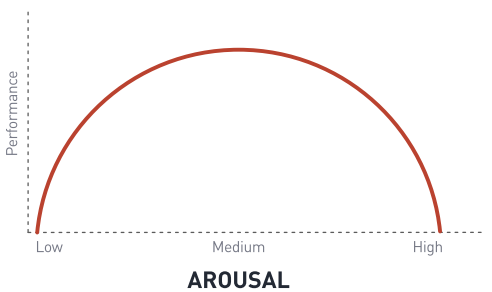

FIGURE 11. The Yerkes-Dodson Law describes the optimal relationship between arousal or pressure and performance; too much pressure is as damaging as too little. take over and we focus on self-preservation. When fear prevails, interactions cease and the hope that anyone will speak up is lost. Still, learning is best with an emotional connection. It enhances relevance.

The old-school cardiac surgeons who inspire fear are not only unpopular today, they are counterproductive. They also doom themselves to living the same frustrations day after day and year after year. How many times have we seen these individuals angry because the staff keeps making the same mistakes over and over: "Why don't they learn?" Perhaps the problem is us and not them. Bullying quite literally shuts down learning.

We can change that. It is entirely within our power to change the nature of the interactions we have within our teams, and we can do it today. No hospital committee or departmental approval is required. You cannot solve all of the problems in your workplace, but you do have an enormous impact on those individuals around you. Everyone is watching you.

I think Dad would say it is our responsibility to optimize the performance of the team. It is our responsibility to create a culture of learning. And Dad would remind me that the foundation of that leadership is respect: "He who feels and hence manifests the respect that is due to others cannot fail to inspire in them regard for himself...."2

And what about that brutal honesty? That, too. Recognizing and sharing our failures with the team at mortality and morbidity conference or during a debriefing after a case. Learning is a process of action and reflection. We learn from failure. The mistakes that haunt me are the ones I did not learn from. We must confront our failure; we must embrace it. We must wring every drop of learning out of it. And we should do so together with our team. Learning is the glue that will bind you together and make you stronger.

Because growing stronger is the point. Nicholas Taleb coined the term antifragile. The opposite of fragile is not resilience. Resilience means a return to the former state. The opposite of being destroyed by failure is being made stronger by it - the way our muscles respond to exercise.

It is what happened in Boston just a few hundred yards from here on April 15, 2013. Two bombs were set off. Three spectators were killed. Athletes and spectators alike lost legs. And the community coalesced to capture the perpetrators and we took back our city. The following year there were more runners than ever before, and more spectators. And since then many of those injured have come back and run again.

This is antifragile.

Isn't this what we want of our surgical teams? Remember that every time you enter the operating room-and for that matter the intensive care unit or the step-down unit as well-you are leading the team. What kind of team will it be? You can choose. Will it be a 
safe learning environment in which diverse perspectives are encouraged and respected? Where you solve problems together rather than alone? You can lead them with passion and with intention.

What I learned as an intern was wrong-trust your team. You need them. The patient needs them.

So there you have it, Dr Moon. Not a single mention of aviation and I only used the word error a few times! We live in a complex world that is hard to understand. Random chance plays an enormous role-more than we like to recognize. We are not in control of it all. But we can cope. We can manage. Together. We can learn together.

So with that I will close and make 1 final request, especially of all you task-oriented personalities in the room. Feeling and knowing are connected. Do something today that lets the people you love feel-not just know-but feel how much they mean to you.

\section{Webcast}

You can watch a Webcast of this AATS meeting presentation by going to: https://www.aats.org/aatsimis/videos/0501-17_BallroomABC_1125_Sundt.mp4.

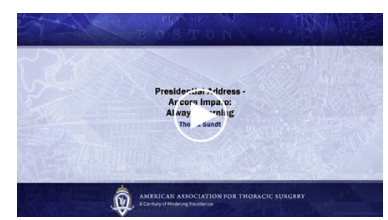

\section{References}

1. Roosevelt T. Citizenship in a republic [speech]. Sorbonne; April 23, 1910; Paris, France.

2. Schofield J. Schofield's definition of discipline [graduation address]. West Point; August 11, 1879; West Point, NY. 


\section{APPENDIX 1. SUGGESTED READING Complexity}

Gleick J. Chaos: The Making of a New Science. New York: Penguin Books; 1987. This should be your first book on the topic of chaos theory. Well written for the lay reader. Not cited directly but a foundational book.

Kluger J. Simplexity; Why Simple Things Become Complex (And How Complex Things Can Be Made Simple). A very enjoyable read-the author wrote Apollo 13 on which the movie was based-Kluger writes for the lay audience and bridges the gap between theory and the real world with lots of examples. A fun book.

Mlodinow L. The Drunkard's Walk; How Randomness Rules Our Lives. New York: Random House; 2008. A very well-written and entertaining book, it is much more readable that Taleb, again with many very real examples. Highly recommended.

Perrow C. Normal Accidents; Living with High-Risk Technologies. Princeton, NJ: Princeton University Press; 1999. First published by Basic Books in 1984, Perrow started writing the book in the fall of 1979, the year of the Three Mile Island accident. A sociologist, he reviews this and other industrial accidents (some in aviation but more in other complex, high-risk, and high-consequence industries-remember Texas City, Texas?). The inevitability of failures is an important and fundamental observation. A good read!

Prigogine I. The End of Certainty; Time, Chaos, and the New Laws of Nature. New York: The Free Press: 1996. A surprisingly readable book about nonequilibrium physics, probability, irreversible processes, and time. Some dense bits in the middle (chapters 5 and 6), but well worth the effort.

Taleb NN. Fooled by Randomness. New York, Random House; 2001. The Black Swan; The Impact of the Highly Improbable. New York: Random House; 2007. Antifragile; Things That Gain from Disorder. New York: Random House; 2012. Three books mentioned from this author, all worthwhile and all a bit tough to read. He is brilliant, irreverent. and scattered. I recommend reading his books quickly and at a high level to pick up the fundamental ideas, which are terrific. Important concepts for us all.

\section{Cognition}

Abbott EA. Flatland; A Romance in Many Dimensions. Cambridge, MA: Perseus Publishing; 2002. This is an annotated version with introduction and notes by Ian Stewart. A bit challenging, and so I think the notes are helpful. Written in Victorian times, it is a social satire as well as a popularization of scientific thinking of the time around the 4th dimension, foreshadowing Einstein's theory of relativity. You'll see it pop up in Taleb's work as well!

Damasio A. Descartes' Error; Emotion, Reason and the Human Brain. New York: Penguin Books; 2005. Originally published in 1994, it is a remarkably readable treatment of the neuroscience behind cognition. I'd describe this as a more scientific treatment of the questions Gladwell asks. Super.

Gladwell M. Blink; The Power of Thinking Without Thinking. New York: Little Brown and Company; 2005. One of my favorite authors (why is there only one kind of ketchup when there are so many kinds of tomato sauce?), Gladwell asks important questions. I'd say that not everyone would entirely agree with his answers-but the questions are the important part. Opens your mind.

Kahneman D. Thinking Fast and Slow. New York: Farrar, Straus and Giroux; 2011. He won the Nobel Prize for the work! This one is fundamental

Klein G. Sources of Power: How People Make Decisions. Cambridge, MA: MIT Press; 1998. The Power of Intuition. New York: Doubleday Random House; 2003. Seeing What Others Don't. New York: Public Affairs; 2013. These are all readable and worthwhile, providing a different take on human cognition-what he calls "naturalistic decision making." I am very impressed with Klein's ideas, and he serves as a balance to the work of Kahneman and Tversky, which tends to focus more on the pitfalls and less on the power of human decision making. We need the balance just as we need to guard against the tendency to look at humans only as a "vulnerability" in systems (we hear about "human error" frequently), rather than recognizing humans as sources of resilience and strength through insight, creativity, and complex problem solving. How often do we hear about the heroes that problem solve on the front line-Sully notwithstanding?

Lewis M. The Undoing Project. New York: WW Norton and Company; 2016. Lewis is a superb writer of course and he tells how he became interested in Prospect Theory and the work of the remarkable team of Kahnemean and Tversky. This one is optional - a fun book — and may help to introduce you to the ideas if you are not at all familiar. Certainly and easier place to start that directly with Kahneman!

Schulz K. Being Wrong; Adventures in the Margin of Error. New York: HarperCollins; 2010. There are a lot of books out now on the subject of making mistakes and being wrong. It seems a new one has just been published every time I walk through an airport bookstore. But if you read just one-read this one. She has a terrific TED talk, too, if you have 17 minutes to spare.

\section{Learning and Teams}

Cozolino L. The Social Neuroscience of Education; Optimizing Attachment and Learning in the Classroom. New York: WW Norton and Company; 2013. A gift to me from Ross and Jamie Ungerlieder, it is a scholarly book and was the foundation of my statements about how we must treat our team to optimize learning. 
Edmondson AC. Teaming. In: How Organizations Learn, Innovate, and Compete in the Knowledge Economy. San Francisco, CA: John Wiley and Sons; 2012. A quick read about the culture required to create a team/organization that learns as it executes. The best of many books I've read about what it takes to optimize team performance. Definitely a worthwhile read.

Page SE. The Difference; How the Power of Diversity Creates Better Groups, Firms, Schools and Societies. Princeton, NJ: Princeton University Press; 2007. A member of the Santa $\mathrm{Fe}$ Institute, this guy makes sophisticated mathematical proofs to the value of diversity. Fantastic. Had to read it a couple of times, though. His video lectures available from The Great Courses distributed by The Teaching Company (www.thegreatcourses.com) helped me understand it-I think!

Pink DH. Drive. In: The Surprising Truth About What Motivates Us. New York: Riverhead Books, The Penguin
Group; 2011. A very readable book. He contrasts externally motivated (money, power, recognition, etc) and internally motivated (master, autonomy, and purpose) individuals. A great airplane book-you'll finish it before you land.

Waldrop MM. Complexity; The Emerging Science at the Edge of Order and Chaos. New York: Simon and Schuster; 1992. Another very nice introduction of the concepts of chaos and complexity, told as a history of the subject focusing on individual scientists and the Santa Fe Institute.

Weick KE, Sutcliffe KM. Managing the Unexpected; Resilient Performance in an Age of Uncertainty. San Francisco, CA: Jossey-Bas; 2007. The nuclear power accidents at Three Mile Island and Chernobyl, the Petrochemical disaster at Bhopal, the Challenger explosion, among other industrial accidents, inspired analysis of high reliability with an eye toward learning lessons that can be applied in a variety of settings. The concepts are directly applicable to surgery. Shouldn't we be "high reliability"? 